\title{
Multivariate hydrological data assimilation of soil moisture and groundwater head
}

\author{
Donghua Zhang ${ }^{1}$, Henrik Madsen ${ }^{2}$, Marc E. Ridler ${ }^{2}$, Jacob Kidmose ${ }^{3}$, Karsten H. Jensen ${ }^{1}$, and Jens C. Refsgaard ${ }^{3}$ \\ ${ }^{1}$ Department of Geosciences and Natural Resource Management, University of Copenhagen, Copenhagen, Denmark \\ ${ }^{2}$ DHI, Hørsholm, Denmark \\ ${ }^{3}$ Geological Survey of Denmark and Greenland (GEUS), Copenhagen, Denmark
}

Correspondence to: Donghua Zhang (donghua.zhang@ign.ku.dk)

Received: 15 March 2016 - Published in Hydrol. Earth Syst. Sci. Discuss.: 5 April 2016

Revised: 7 August 2016 - Accepted: 26 August 2016 - Published: 26 October 2016

\begin{abstract}
Observed groundwater head and soil moisture profiles are assimilated into an integrated hydrological model. The study uses the ensemble transform Kalman filter (ETKF) data assimilation method with the MIKE SHE hydrological model code. The method was firstly tested on synthetic data in a catchment of less complexity (the Karup catchment in Denmark), and later implemented using data from real observations in a larger and more complex catchment (the Ahlergaarde catchment in Denmark). In the Karup model, several experiments were designed with respect to different observation types, ensemble sizes and localization schemes, to investigate the assimilation performance. The results showed the necessity of using localization, especially when assimilating both groundwater head and soil moisture. The proposed scheme with both distance localization and variable localization was shown to be more robust and provide better results. Using the same assimilation scheme in the Ahlergaarde model, groundwater head and soil moisture were successfully assimilated into the model. The hydrological model with assimilation showed an overall improved performance compared to the model without assimilation.
\end{abstract}

\section{Introduction}

Integrated hydrological modelling plays an important role in water resources management to develop sustainable environmental and economic schemes. Integrated models offer advantages with respect to incorporating different physically based hydrological processes and providing a consistent prediction of different hydrological variables. Hydrological data assimilation aims to utilize the information embedded in hydrological observations for improving the performance of hydrological models. Data assimilation (DA) has the advantage of exploiting both imperfect models and limited observations, considering uncertainties in both to provide a more accurate prediction.

Groundwater head and soil moisture are two key variables in hydrological modelling of the saturated and unsaturated zones respectively. Several applications of assimilating each variable individually in either groundwater models or land surface models have been reported. For example, Chen and Zhang (2006) presented an application of the ensemble Kalman filter (EnKF) to a groundwater flow model, with updating of both groundwater head and hydraulic conductivity. De Lannoy et al. (2007) applied the EnKF for soil moisture state and bias estimation in a small field using the CLM (Community Land Model). There are also a few studies with assimilation of both groundwater head and soil moisture. For example, Visser et al. (2006) used groundwater head and soil moisture data to re-calibrate the SWAP (Soil, Water, Atmosphere and Plant) model online using a simplified form of Newtonian nudging (NN), and showed superior results compared to offline calibration. Camporese et al. (2009a) used Newtonian nudging and the EnKF to assimilate synthetic observations in a coupled surface-subsurface flow model.

The use of multivariate assimilation in integrated hydrological models provides great potential to deepen our understanding of the value of different measurement data. Several studies of multivariate assimilation applications in integrated hydrological models have been reported. Xie and Zhang (2010) applied EnKF to the Soil and Water Assess- 
ment Tool (SWAT), with updating of multiple states and parameters including runoff, soil moisture and evapotranspiration. Camporese et al. (2009b) used EnKF in the CATHY (CATchment HYdrology) model with coupled surface and subsurface flow, to assimilate groundwater head and stream discharge. Rasmussen et al. (2015) assimilated the same variables using the ensemble transform Kalman filter (ETKF) with the MIKE SHE model. Kurtz et al. (2014) jointly assimilated groundwater heads and groundwater temperatures with EnKF using both synthetic and real-world models. Shi et al. (2014) employed EnKF to assimilate multivariate hydrological states in a small catchment modelled by the FluxPIHM land surface model, with a focus on parameter estimation. Lee et al. (2011) used a variational assimilation approach to assimilate streamflow and in situ soil moisture, to correct the soil moisture profiles within the HL-RDHM model. Ridler et al. (2014b) developed a generic DA framework that enables coupling of hydrological models with the OpenDA library (http://www.openda.org) using the OpenMI (Open Model Interface; Gregersen et al., 2007), and applied it with the MIKE SHE model. Han et al. (2015) developed an open-source multivariate DA framework (DasPy) for the Community Land Model. Although many multivariate DA platforms and applications have been reported, assimilating both soil moisture and groundwater head in an integrated hydrological model has not been studied in detail. Representing two important hydrological variables, their observational values by assimilation in integrated hydrological models are explored in this study.

Meanwhile, techniques have been developed for multivariate DA. The most straightforward approach used in integrated models is state augmentation, which is commonly applied with EnKF and its variants, with nearly no additional modifications on algorithms. The observation vector can be extended to accommodate multiple types of observations. Similarly, the state vector can be augmented to include all relevant state variables, and possibly model parameters. The covariance matrix is thereby expanded to a block matrix where each block presents the cross-covariance between variables in the state vector (Montzka et al., 2012). A potential challenge in this respect is that implementing EnKF techniques like localization no longer becomes straightforward. Commonly used localization techniques usually belong to covariance localization (Hamill et al., 2001) or local analysis (Anderson, 2003). When updating a single state variable with corresponding measurements, distance localization is usually used to reduce the impact of long distance sampling errors in the forecast error covariance due to a limited ensemble size. When there is more than one state variable, the degree of localization for each variable needs to be appropriately specified. Another incidental fact in multivariate DA is that the spurious correlation across variables is usually more pronounced, leading to deterioration of the model updating. To overcome this problem, Kang et al. (2011) successfully introduced "variable localization" in addition to distance lo- calization and tested this with the local ensemble transform Kalman filter (LETKF) in a carbon cycle model.

In this study, we systematically investigate the performance of a filter assimilating soil moisture and groundwater head, with respect to the assimilated variable type, localization scheme and ensemble size. The assimilation method is based on the ETKF (Bishop et al., 2001), distance localization using local analysis (Sakov and Bertino, 2010), and variable localization (Kang et al., 2011). The approach is first tested on a catchment of less complexity (the Karup catchment in Denmark) and using synthetically generated data, and later implemented in a larger and more complex catchment (the Ahlergaarde catchment in Denmark) using real data. From the methodology point of view, the novelty of this study is the use of advanced multivariate assimilation methodologies in combination with the application of different localization schemes. From the application point of view, the novelty of this study is to investigate the value of assimilated variables and their impact on other processes through integrated hydrological modelling in a complex catchment using real data.

The paper is organized as follows: the two study areas and the hydrological modelling processes are introduced in Sect. 2; the detailed assimilation methodology is described in Sect. 3; Sect. 4 presents the experimental settings and the assimilation results based on the Karup catchment; Sect. 5 presents the real observations, experimental settings and the results based on the Ahlergaarde catchment; and finally general discussions and conclusions are given in Sect. 6.

\section{Hydrological modelling}

\subsection{Study areas}

Two study areas in Denmark are used in this study. The $440 \mathrm{~km}^{2}$ Karup catchment is located in the centre of Jutland (left in Fig. 1). The land use is mainly agriculture, and topographical elevation is between 20 and $100 \mathrm{~m}$. The catchment lies in an alluvial plain with coarse sandy soils and a strongly groundwater dominated hydrological regime. The Ahlergaarde catchment is located in one of the most irrigated areas of Denmark (right in Fig. 1). Of the total catchment area of $1044 \mathrm{~km}^{2}, 61 \%$ is covered by agricultural crops. The surface geology consists mostly of sand and, also in this catchment, the streamflow is dominated by groundwater inflow.

The Karup catchment is a well-studied catchment in terms of model parameterization and model calibration (Refsgaard, 1997; Madsen, 2003; Zhang et al., 2015). A relatively simple model with a fast computation time was developed for this catchment to test and verify various DA methods. The Ahlergaarde catchment is the research catchment of the Danish Hydrological Observatory (www.hobe.dk, Jensen and Illan- 

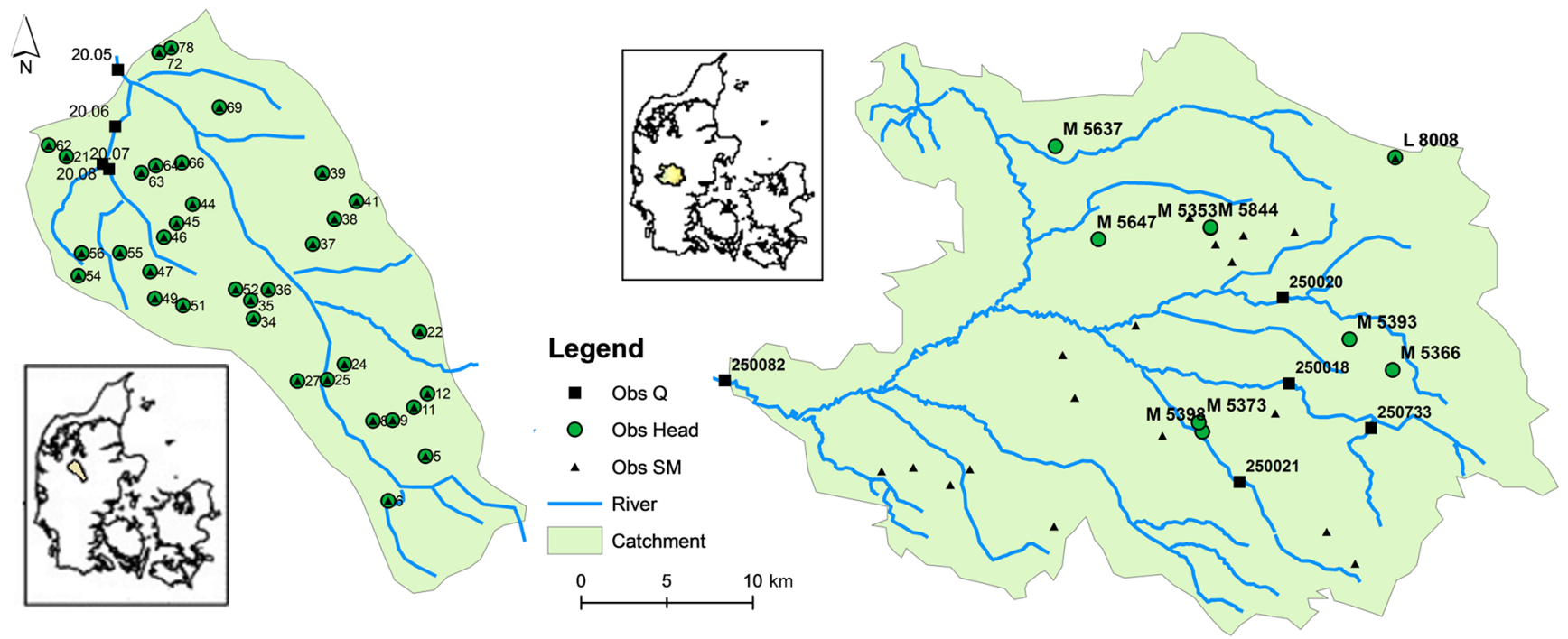

Figure 1. Left: Karup catchment; right: Ahlergaarde catchment. "Obs Q", “Obs Head” and "Obs SM” represent discharge, groundwater head and soil moisture observations respectively used for assimilation.

gasekare, 2001). This study area is ideal for further testing DA methods using real measurements.

\subsection{Hydrological model}

The MIKE SHE hydrological modelling system is used for developing models for the above two catchments. As a physically based distributed hydrological model, MIKE SHE simulates the major processes in the water cycle, including evapotranspiration, overland flow, unsaturated flow, groundwater flow, river flow and the interactions between them. MIKE SHE also has the flexibility of modelling each process at given spatial and temporal resolutions with different complexity. The complexity can be chosen according to the model purpose and data availability (Graham and Butts, 2005).

In the Karup catchment, the modelling is based on the following process descriptions: 2-D groundwater flow is assumed and modelled by one computational layer in the saturated zone, drain flow (pipes/ditches) is described by a simple conceptual relationship and occurs when the groundwater table exceeds the drain level, 1-D unsaturated flow is assumed and based on a simplified gravity-based flow equation, 1-D channel flow is assumed and based on kinematic routing, 2-D overland flow routing is based on the diffusive wave approximation of the Saint-Venant equations, and evapotranspiration is described, including interception, soil evaporation and transpiration by vegetation (DHI, 2015). The numerical discretization in the horizontal plane is a $1000 \times 1000 \mathrm{~m}^{2}$ grid size. The model is forced by station-based daily precipitation and uniform daily values for reference evaporation. In the MIKE SHE model, the temporal resolution is dynamic and differs between the modules. For the maximum allowed time step, $6 \mathrm{~h}$ is specified for overland flow, $6 \mathrm{~h}$ for unsaturated flow and $12 \mathrm{~h}$ for saturated flow respectively.

For the Ahlergaarde catchment, the same model components are included as for the Karup catchment. For computational efficiency, and due to the fact that the exact irrigation information in terms of both location and amount is not known, the irrigation module is not activated in the model. The modelling approaches are the same as for Karup, except that 3-D groundwater flow is considered with six numerical layers defined according to geological stratigraphy. Another main difference is that the model uses a smaller grid size $\left(200 \times 200 \mathrm{~m}^{2}\right)$. The finer model discretization enables the model to utilize finer-resolution system data such as geological stratigraphy, soil type and land use. The model is forced with grid-based daily precipitation, temperature and reference evaporation. In both catchments no-flow boundaries are defined along the catchment borders. The temporal resolution in the model is constrained by maximum time steps of $2 \mathrm{~h}$ for overland flow, $2 \mathrm{~h}$ for unsaturated flow and $6 \mathrm{~h}$ for saturated flow respectively. The model parameterization and model calibration are introduced in Sect. 2.3.

The finer model resolution and increased complexity for the Ahlergaarde catchment increase the simulation time significantly. For example, the average model time step in the groundwater zone decreases from $7.5 \mathrm{~h}$ in the Karup model to $1.3 \mathrm{~h}$ in the Ahlergaarde model. In consequence 1-year model simulation takes less than $1 \mathrm{~min}$ for Karup and around $1 \mathrm{~h}$ for Ahlergaarde. The differences in model resolution and simulation time for the two catchments are summarized in Table 1. 
Table 1. Differences in model resolution and computation time between the two catchments. SZ refers to the saturated zone and UZ to the unsaturated zone; the term "No. of" means "Number of".

\begin{tabular}{lcc}
\hline Catchment & Karup & Ahlergaarde \\
\hline Area & $440 \mathrm{~km}^{2}$ & $1044 \mathrm{~km}^{2}$ \\
Grid size & $1000 \times 1000 \mathrm{~m}^{2}$ & $200 \times 200 \mathrm{~m}^{2}$ \\
No. of grid cells in each layer in SZ & 522 & 26922 \\
No. of layers in SZ & 1 & 6 \\
No. of total grid cells in SZ & 522 & 161538 \\
No. of grid cells in each layer in UZ & 438 & 26097 \\
No. of layers in UZ & 87 & 21 \\
No. of total grid cells in UZ & 38106 & 548037 \\
Computational time for 1-year simulation & Less than 1 min & Around 1 h \\
\hline
\end{tabular}

\subsection{Model calibration}

For both catchments, the model parameterization is kept relatively simple yet able to represent the overall spatial patterns of key model parameters. When specifying the parameter values for each property class (e.g. geological unit, vegetation type and soil type), most of the parameters cannot be estimated empirically or directly inferred from data. Thus model calibration is usually required using an optimization algorithm like AUTOCAL (Madsen, 2003) or PEST (Doherty, 2010).

For the Karup model, the most sensitive parameters describing the hydraulic properties of the river, unsaturated zone, saturated zone, and river-aquifer interaction are calibrated using AUTOCAL (Zhang et al., 2015). As calibration data we use 35 biweekly groundwater head observations and daily observations of stream discharge for a 6-year period (1969-1974) (Fig. 1).

The Ahlergaarde model is calibrated using PEST version 11.8 (Doherty, 2010). The data used in the calibration are groundwater head observations (466 in total) scattered over the catchment (not shown in Fig. 1) and river discharge observations from the period of 2006-2009. In most of the groundwater wells only one observation is available for the entire calibration period and only a few wells have time series. Discharge data comprise time series of daily values from five stations (Fig. 1). Similar to the Karup catchment, the most sensitive parameters ( 7 parameters) are selected for calibration, with 13 parameters tied to those 7 parameters. The calibrated values for those 7 parameters are listed in Table 2 (first 7 parameters) together with the confidence intervals obtained from the inversion process. The remaining parameters in Table 2 are not included for calibration, but are only selected for perturbation, with a detailed explanation given in Sect. 5. The original calibrated model uses a simplified twolayer approach to simulate unsaturated flow and evapotranspiration, where the average soil moisture is calculated for the root zone and the layer below the root zone. In order to assimilate in situ soil moisture data at different depths, the gravity flow module is used as a replacement for the two- layer approach in the unsaturated zone. By doing so, soil moisture can be calculated at different depths. The overall modelling performance in terms of water balance and discharge dynamics becomes marginally reduced compared to the original calibration results.

\section{Data assimilation}

\subsection{Ensemble transform Kalman filter}

The assimilation algorithm used in this study is the ETKF, which is a popular variation of the EnKF (Evensen, 2003). Similar to the EnKF, the ETKF is a Monte Carlo implementation of the Kalman filter, which approximates the posterior probability distribution conditioned on a series of observations, and is able to deal with non-linear models. In comparison to the EnKF, the ETKF is a deterministic filter, as it does not require additional observation perturbations. The ETKF was originally introduced by Bishop et al. (2001) and later modified to be unbiased (Wang et al., 2004). As an ensemblebased deterministic filter, it has the advantage of calculating the forecast error covariance efficiently. It is also computationally faster than the ensemble square root filter (EnSRF) (Whitaker and Hamill, 2002).

To develop the DA algorithm, a state-space formulation is needed:

$\boldsymbol{X}_{t+1}=M\left(\boldsymbol{X}_{t}, U_{t}, \theta\right) \approx M_{\mathrm{d}}\left(\boldsymbol{X}_{t}, \widetilde{U}_{t}, \widetilde{\theta}\right)$,

where $M$ is the stochastic model operator based on the numerical solution to the MIKE SHE equations, $M_{\mathrm{d}}$ is the deterministic MIKE SHE model operator, $\boldsymbol{X}_{t}$ and $U_{t}$ are the state vector and model forcing respectively at time step $t$, and $\theta$ stands for the model parameters. $\widetilde{U}_{t}$ and $\widetilde{\theta}$ are the perturbed forcing and parameters respectively. Note that the stochastic model operator $M$ is approximated by the deterministic MIKE SHE model, taking both model forcing uncertainty and model parameter uncertainty into account (Zhang et al., 2015). In both models, precipitation and potential evapotranspiration are perturbed by adding a random Gaussian 


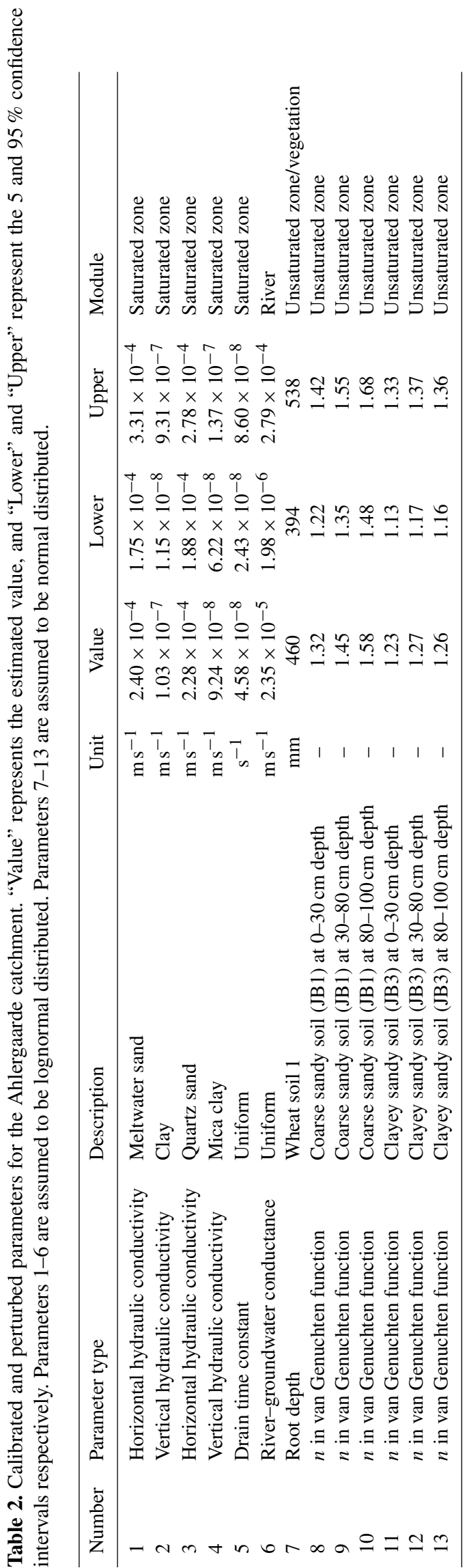

noise to the actual value. The parameter uncertainty is described mainly using the covariance estimated from calibration. The selected parameters are assumed to be multivariate normal/lognormal distributed and perturbed using Latin hypercube sampling based on the associated parameter covariance. Additional post-processing steps are used to ensure that the perturbed parameters are still within realistic parameter ranges.

At time $t+1$, the observations can be written as

$\boldsymbol{Y}_{t+1}=\mathbf{H} \boldsymbol{X}_{t+1}+\varepsilon_{t+1}, \varepsilon_{t+1} \sim N\left(0, \mathbf{R}_{t+1}\right)$,

where $\boldsymbol{Y}$ denotes the observation vector, and $\mathbf{H}$ is the linear mapping operator specifying the deterministic relationship between observations and model state $\boldsymbol{X}$. In this study, the observations are either groundwater head, soil moisture, or both. Similarly, the state vector consists of groundwater head, soil moisture, or both. When two variables are assimilated, the state vector is augmented to accommodate both variables at all computational cells, and the observation operator $\mathbf{H}$ is revised to select the correct model equivalent and compare it with the corresponding observation. The observation noise is assumed to be Gaussian, temporally uncorrelated, and spatially uncorrelated, with the zero mean and a prescribed constant standard deviation $\sigma_{\mathrm{r}}$ for each observation type. Therefore, $\mathbf{R}_{t+1}$ is a diagonal matrix with constant values for each observation along the diagonal (i.e. $\mathbf{R}_{t+1}=$ $\left.\operatorname{diag}\left(\sigma_{\mathrm{r} 1}^{2}, \ldots, \sigma_{\mathrm{r} 1}^{2}, \sigma_{\mathrm{r} 2}^{2}, \ldots, \sigma_{\mathrm{r} 2}^{2}, \ldots, \sigma_{\mathrm{r} o}^{2}, \ldots, \sigma_{\mathrm{r} o}^{2}\right)\right)$ for total $o$ observation types.

The forecast state distribution can be estimated by a finite number $m$ of model realizations from Eq. (1) as follows:

$\mathbf{X}^{\mathrm{f}}=\left[\boldsymbol{x}^{\mathrm{f} 1}, \boldsymbol{x}^{\mathrm{f} 2}, \ldots, \boldsymbol{x}^{\mathrm{f} m}\right]$,

where the superscript $f$ stands for "forecast".

The forecast error covariance can be written as

$\mathbf{P}^{\mathrm{f}}=\mathbf{X}^{\prime \mathrm{f}}\left(\mathbf{X}^{\prime \mathrm{f}}\right)^{T} /(m-1)$,

where $\mathbf{X}^{\prime}{ }^{f}$ is the forecast ensemble perturbation

$\mathbf{X}^{\prime \mathrm{f}}=\left[\boldsymbol{x}^{\mathrm{f} 1}-\overline{\mathbf{X}^{\mathrm{f}}}, \boldsymbol{x}^{\mathrm{f} 2}-\overline{\mathbf{X}^{\mathrm{f}}}, \ldots, \boldsymbol{x}^{\mathrm{f} m}-\overline{\mathbf{X}^{\mathrm{f}}}\right]$

and $\overline{\mathbf{X}^{f}}$ is the ensemble mean. After assimilation, both the analysed state mean and the analysed error covariance can be calculated:

$\overline{\mathbf{X}^{\mathfrak{a}}}=\overline{\mathbf{X}^{\mathrm{f}}}+\mathbf{K}\left(\boldsymbol{Y}-\overline{\mathbf{H} \mathbf{X}^{\mathrm{f}}}\right)$,

$\mathbf{P}^{\mathrm{a}}=(\mathbf{I}-\mathbf{K} \mathbf{H}) \mathbf{P}^{\mathrm{f}}$,

where the superscript a stands for "analysed", and $\mathbf{K}$ is the Kalman gain defined as

$\mathbf{K}=\mathbf{P}^{\mathrm{f}} \mathbf{H}^{T}\left(\mathbf{H} \mathbf{P}^{\mathrm{f}} \mathbf{H}^{T}+\mathbf{R}\right)^{-1}$. 
In practise, $\mathbf{P}^{\mathrm{a}}$ is never explicitly calculated, and only the ensemble mean and ensemble anomalies are updated. Based on factorizing Eq. (7) on both sides, the following equation is obtained:

$\mathbf{X}^{\prime \mathrm{a}}=\mathbf{X}^{\prime \mathrm{f}} \mathbf{T}$

where

$\mathbf{T}=\left[\mathbf{I}+\left(\mathbf{H} \mathbf{X}^{\prime \mathrm{f}}\right)^{T} \mathbf{R}^{-1} \mathbf{H} \mathbf{X}^{\prime \mathrm{f}} /(m-1)\right]^{-1 / 2} \mathbf{U}$

and $\mathbf{U}$ is an arbitrary orthonormal matrix $\mathbf{U} \mathbf{U}^{T}=\mathbf{I}$.

The MIKE SHE model is coupled with a generic DA library that handles the time propagation and update of the model ensemble based on the ETKF (Ridler et al., 2014b).

\subsection{Localization}

In ensemble-based Kalman filter systems, the forecast state and its associated uncertainty are represented by a limited ensemble of realizations. The undersampling can lead to filter inbreeding and spurious correlations in the error covariance matrix, which potentially can lead to filter divergence. Localization is a commonly used technique when applying ensemble-based Kalman filters to overcome this problem. By artificially reducing the impacted spatial domain of observations, the spurious correlation between two remote locations can be avoided. For each element in the state vector, local analysis (LA, Sakov and Bertino, 2010) is used to approximate the state error covariance within the local window. The ensemble anomalies outside this local window will be unchanged during the filter updates. However, LA is usually applied to a single state variable for which certain spatial correlations exist. When the state vector contains two or more variables, specifying the localization degree for each variable is not straightforward. More importantly, correlations between variables are not clear, because physical distances between variables may not exist. Similar to the approach by Kang et al. (2011), we introduced different variable localization schemes based on whether the correction of one variable can impact the update of other variables. In this section, the distance localization will be introduced first, followed by the variable localization.

\subsubsection{Distance localization}

We formulate the distance-localized ETKF equations with similar notations as in Sakov and Bertino (2010). A variable with an upper accent " $i$ " means a local variable, which is used to update the $i$ th element of the state vector. During the updating with localization, $i$ is looped for each element in the state vector. For example, $\mathbf{K}$ means the local Kalman gain and $\stackrel{i}{\boldsymbol{Y}}$ denotes the local observations associated with the $i$ th element in the state vector. In matrices, the subscript " $i$, ," refers to the $i$ th row. To avoid the occasional sudden changes of analysis from one state vector element to the next one when an observation just arrives or exits the local window, an ensemble tapering with a distance-based taper function $f($.$) is used to ensure the impact of the observation is$ reduced gradually from the centre to the boundary within the local domain (Sakov and Bertino, 2010).

Therefore, to update the $i$ th element, the localized ETKF equations (Eqs. 6, 9, and 10) become

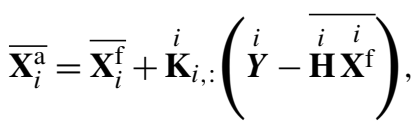

$\stackrel{i}{\mathbf{K}_{i,:}}=\mathbf{X}_{i,:}^{\text {ff }} \stackrel{i}{\mathbf{S}^{T}}\left(\mathbf{I}+\mathbf{S S}^{i} \mathbf{S}^{T}\right)^{-1} \mathbf{R}^{-1 / 2} / \sqrt{m-1}$,

$\mathbf{X}_{i,:}^{\prime \mathrm{a}}=\mathbf{X}_{i,:}^{\prime \mathrm{f}} \stackrel{i}{\mathbf{T}}$,

$\stackrel{i}{\mathbf{T}}=\left(\mathbf{I}+\stackrel{i}{i} \mathbf{S S}^{T}\right)^{-1 / 2} \mathbf{U}$,

$\stackrel{i}{\mathbf{S}} \stackrel{\text { def }}{=} \stackrel{i}{\mathbf{R}} \stackrel{i}{\mathbf{H}} \mathbf{X}^{\mathrm{f}} / \sqrt{m-1}$.

During the update, the observation $\boldsymbol{Y}$, innovations $\boldsymbol{Y}-$ $\mathbf{H X}^{\mathrm{f}}$, observation error variance $\mathbf{R}$ and ensemble observation anomalies $\mathbf{H X}^{\prime}{ }^{f}$ are tapered in line with the taper function $f($.). The LA taper function is usually determined by the distance between two model points, which decreases from one to zero as the distance increases. Different choices of distance-dependent covariance functions can be used according to dimension and physical property. For example, Sakov and Bertino (2010) use the Gaspari and Cohn 1-D taper function to compare different localization methods. Ridler et al. (2014a) use a 2-D squared exponential covariance function as a taper function to localize the soil moisture updating. In this study, due to the difference in variable type and variable dimension, the taper function is chosen to be case specific based on the 2-D squared exponential covariance function.

For groundwater heads, in both catchments, the LA taper function is chosen to have a radius of $5 \mathrm{~km}$, to include a relatively large number of observations to correct each node, and also to provide a larger spatial influence of the update. For the Ahlergaarde catchment where the groundwater is modelled in 3-D, the LA localization is applied to each layer with the same radius. For soil moisture, the measurements usually represent a relatively smaller spatial scale. In both catchments, localization scales are specified to ensure that the state correction from the assimilated observation is localized. Horizontally, the taper function is chosen to have a radius of 1$5 \mathrm{~km}$ at the layer where soil moisture is screened. Because most of the data are measured in the surface and near-surface soil $(5-25 \mathrm{~cm}$ depth), the water content in the upper layers (e.g. within 1 or $0.5 \mathrm{~m}$ depth) is expected to have a larger correction compared to the water content in deeper layers. Therefore, at depths below the soil moisture observation, we 


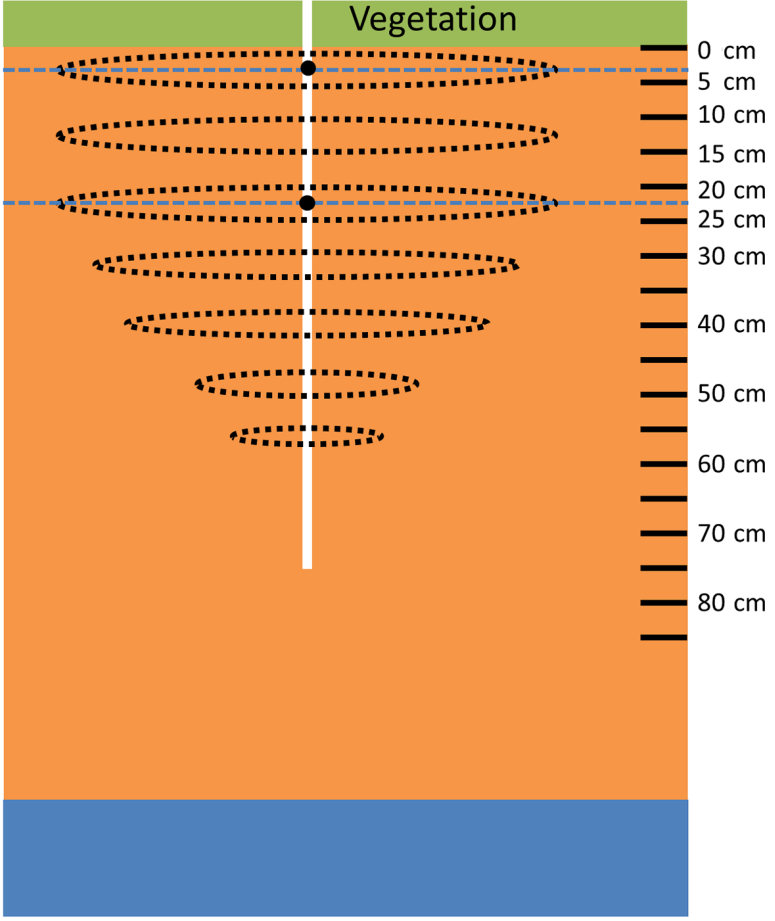

Figure 2. Sketch of the localization scheme for soil moisture at a site where soil moisture is measured at $0-5$ and $20-25 \mathrm{~cm}$ (marked by filled black circles). The depths on the right represent the numerical layers. The dotted-line ovals indicate the localization areas for each layer, where the cut-off values of the covariance function increase quadratically from depths $20-25 \mathrm{~cm}$ downward.

add a quadratically increasing cut-off value for the covariance function as the depth increases (Fig. 2).

\subsubsection{Variable localization}

Variable localization is an option when assimilating both groundwater head and soil moisture. Variable localization determines whether the information from one variable can be used to update the other. When variable localization is off, no matter the available observation type (groundwater head, soil moisture or both), all observation data are used to update the ensemble mean (Eq. 11) and anomaly (Eq. 13) for both variables. Therefore the correlation between the variables is kept during the assimilation. In addition, if distance localization is applied, the correlation exists in localized domains between variables. When variable localization is applied, each observation type will only be used to update its own type of state variable. Other variables in the state vector will be unchanged during update. If distance localization is applied, state updates are spatially localized within its own type of variable.

Practically, the variable localization can be done by slight modifications to Eqs. (11)-(15). The taper function is extended to have an "if/else" statement prior to the existing distance-based taper function, depending on whether variable localization is chosen or not. Here we explain the process of updating one element when variable localization is applied. When looping over the $i$ th element in the state vector, the state in the "local" window is selected first by ensuring it has the same variable type as in the $i$ th element, then calculating the weight according to the distance from the $i$ th element. For example, when updating soil moisture in a grid cell, the ensemble mean and anomaly will be unaffected by soil moisture observations outside the local window, as well as by groundwater head observations.

\section{Study in the Karup catchment}

In the Karup catchment experiment, the calibrated model described in Sect. 2.3 is used as the deterministic model. The calibrated model has relatively good performance in reproducing the observations, with an averaged root mean square error (RMSE) of around $1 \mathrm{~m}$ for groundwater head and a Nash-Sutcliffe score of 0.4 for discharge at the catchment outlet. In Fig. 3 are shown examples demonstrating the model performance for a groundwater head station and a discharge station.

The ensemble is generated by adding an appropriate model error to the deterministic model. Similarly, given the predefined model error, a single random model realization is generated to be the "true" model. Note that the "true" model here is only an assumption of reality. The model error is defined by perturbing both model forcing (precipitation and potential evapotranspiration) and selected model parameters (Zhang et al., 2015). The ensemble runs freely from 1 December 1969 to 1 January 1973 as a warm-up period. During the warmup period, each ensemble member starts with the same initial condition but has different model trajectories because of different forcing and parameter values. It is important to generate an ensemble with a realistically large spread, so that the model uncertainty can be fully represented by the ensemble.

The synthetic observations to be assimilated are generated from the "true" model. Given the true realization, by adding measurement errors to observed model variables at a given time and location, a set of synthetic observations can be produced. Both groundwater head and soil moisture (depths of 5 and $25 \mathrm{~cm}$ ) are extracted from the same 35 locations as the actual head observations (Fig. 1). The observation noise for each variable is assumed to be white Gaussian, with a homogeneous and constant standard deviation of $0.15 \mathrm{~m}$ for head and $5 \%$ for the soil volumetric water content. Due to the fact that groundwater head has a much slower dynamic compared to the unsaturated flow, we assimilate head with weekly frequency and soil moisture with daily frequency.

After the warm-up period, the synthetic observations are assimilated over a 1-year period from 1 January 1973 to 1 January 1974. Given the fact that the "true" model is known, the deterministic model can be seen as an imperfect 

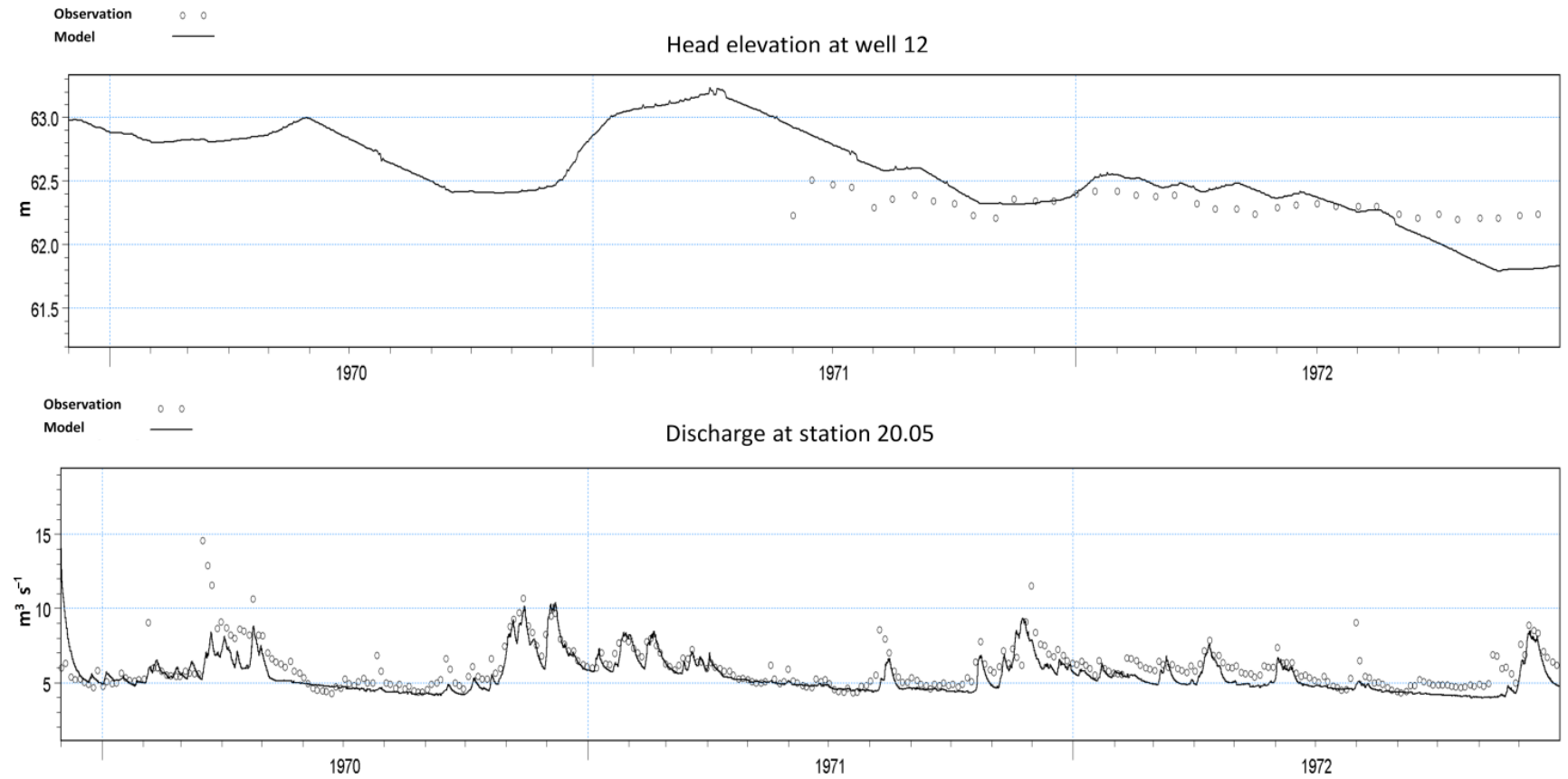

Figure 3. Observed and simulated water table at well 12 (top panel) and hydrograph at station 20.05 (bottom panel) in the Karup catchment.

model. With the purpose of combining the imperfect model and the synthetic observations, different experiments are carried out to investigate under which conditions the assimilation results are most similar to the "true" model. These experiments are designed using different observation variables, localization schemes and ensemble sizes. The assimilation performance can be assessed by taking the RMSE between the model simulation and the true state for selected variables over the entire domain at all available time steps. As soil moisture measurements are depth-dependent, RMSE is calculated for each depth (each layer). Here we not only show the results from 5 and $25 \mathrm{~cm}$ depths where observations are assimilated, but also at $50 \mathrm{~cm}$ depth. In addition, other hydrological responses in the form of evapotranspiration and discharge are evaluated.

\subsection{Univariate assimilation}

When a single variable is assimilated (groundwater head or soil moisture), the state vector only consists of the corresponding observed variable at all model grid cells. Therefore, the remaining variables will not be changed directly from the filter. However, as both the groundwater component and unsaturated zone are fully coupled with surface water and other model components, the whole model state will be affected from updating a single variable. Different experiments are carried out using an ensemble size of 60 :

- NoDA: deterministic model without DA;

- DA_H: assimilating head without localization;
- DA_HLoc: assimilating head with a horizontal localization radius of $5 \mathrm{~km}$;

- DA_SM5: assimilating soil moisture at $5 \mathrm{~cm}$ depth without localization;

- DA_SM5Loc: assimilating soil moisture at $5 \mathrm{~cm}$ depth with localization of a $5 \mathrm{~km}$ spatial radius within $1 \mathrm{~m}$ depth;

- DA_SM5LocSmall: assimilating soil moisture at $5 \mathrm{~cm}$ depth with localization of a $3 \mathrm{~km}$ spatial radius within $50 \mathrm{~cm}$ depth;

- DA_SMBoth: assimilating soil moisture at both 5 and $25 \mathrm{~cm}$ depths without localization;

- DA_SMBothLoc: assimilating soil moisture at both 5 and $25 \mathrm{~cm}$ depths with a $5 \mathrm{~km}$ spatial radius within $1 \mathrm{~m}$ depth.

As the experiment names indicate, $\mathrm{H}$ stands for groundwater head and SM stands for soil moisture. Loc indicates that localization is added to the experiment.

Results from the DA experiments are shown in Fig. 4. When head is assimilated (DA_H), the RMSE for head improves significantly from 0.21 to $0.08 \mathrm{~m}$. However, soil moistures at the three depths are basically not influenced. When localization is used (DA_HLoc), the corrections are localized around the head observations and the overall performance is slightly degraded.

When soil moisture at $5 \mathrm{~cm}$ depth is assimilated alone without localization (DA_SM5), the soil moisture profile 


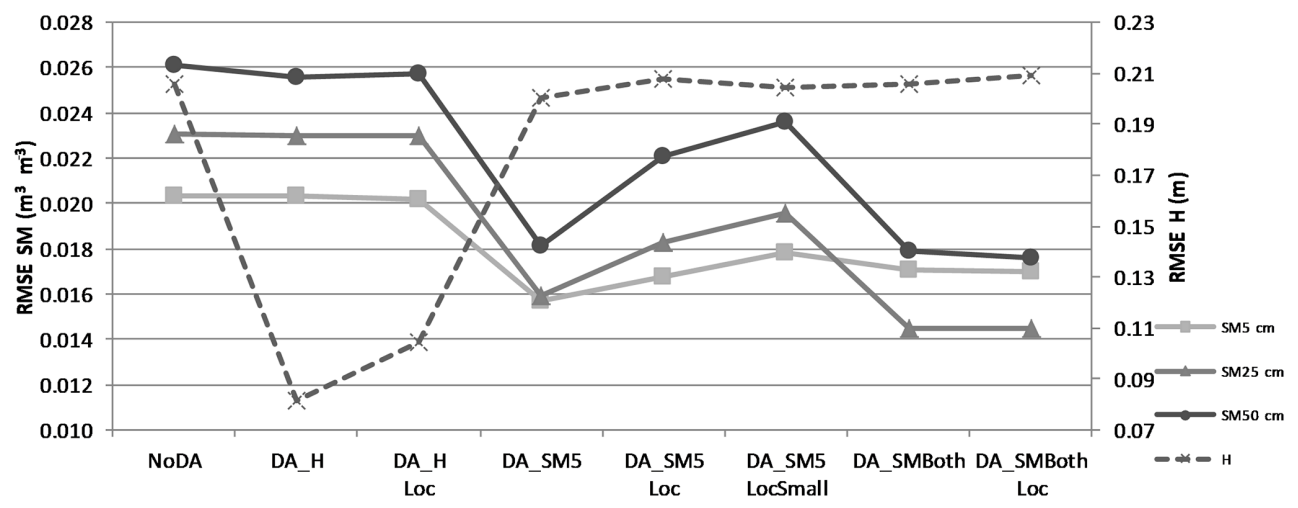

Figure 4. Spatially and temporally averaged RMSE of groundwater head and soil moisture at different depths for each univariate assimilation experiment in the Karup catchment. The left axis represents soil moisture and the right axis head.

clearly improves at all three depths. However, for head the performance is almost the same as in the deterministic model. Different localization scales have been tested with assimilating soil moisture at $5 \mathrm{~cm}$ depth (DA_SM5Loc and DA_SM5LocSmall). The result indicates that the overall assimilation performance decreases with a smaller localization scale.

When soil moisture at both 5 and $25 \mathrm{~cm}$ depths is assimilated (DA_SMBoth and DA_SMBothLoc), the performances are similar regardless of localization. Compared to the result from DA_SM5, the soil moisture estimate improves at $25 \mathrm{~cm}$ but slightly worsens at $5 \mathrm{~cm}$. Compared to DA_SM5Loc, the results show some improvements at 25 and $50 \mathrm{~cm}$. Again, groundwater head is hardly influenced by assimilating soil moisture. In the following experiments, we include observations at both 5 and $25 \mathrm{~cm}$ when soil moisture is assimilated.

As we can see from Fig. 4, univariate assimilation with localization improves the estimate of the assimilated variable albeit the results are slightly worse compared to the experiment without localization in the case of assimilating head or soil moisture at $5 \mathrm{~cm}$. This could be explained as follows. Firstly, spatial correlations are affected by the catchment size and the relatively large grid size used. Pronounced correlations exist even between remote locations, and therefore localization may cut off true correlations, which leads to a worse result overall. Secondly, there are a relatively large number of observations compared to the size of the state vector, which reduces the problem of spurious correlation. Study shows that there is a strong relationship between the significance of spurious correlation and the number of observations (Rasmussen et al., 2015). Localization is more effective to reduce spurious correlation when the number of observations is relatively small. We also notice that the $50 \mathrm{~cm}$ depth soil moisture has an overall larger error compared to the surface layer; this is due to the fact that the soil moisture cell saturation in the deeper layer is more sensitive to the parameter uncertainty, which makes the deeper layer more difficult to reproduce.

\subsection{Multivariate assimilation}

In this section, several experiments assimilating both groundwater head and soil moisture are carried out with a focus to test different localization schemes. The abbreviations D and $\mathrm{V}$ indicate distance localization and variable localization respectively.

- DA_HSM: assimilating both head and soil moisture (at both 5 and $25 \mathrm{~cm}$ depths) without localization to any variable.

- DA_HSMLoc_DV: assimilating both head and soil moisture (at both 5 and $25 \mathrm{~cm}$ depths) with variable localization and with distance localization applied to head (same as DA_HLoc) and soil moisture (same as DA_SMBothLoc).

- DA_HSMLoc_D: assimilating both head and soil moisture (at both 5 and $25 \mathrm{~cm}$ depths) without variable localization, but with distance localization applied to head (same as DA_HLoc) and soil moisture (same as DA_SMBothLoc).

- DA_HSMLoc_V: assimilating both head and soil moisture (at both 5 and $25 \mathrm{~cm}$ depths) with variable localization, but without distance localization to any variable.

Results from the DA experiments are shown in Fig. 5. When neither distance localization nor variable localization is used, all observations are used to update the state in all grid cells for each variable (DA_HSM). In this case the estimated correlations between groundwater head and soil moisture are used in the update. The DA results show improved performance for soil moisture at 5 and $25 \mathrm{~cm}$, but much worse performance at $50 \mathrm{~cm}$ as well as for groundwater head. In the current filter settings the full state covariance matrix contains unrealistic, spurious correlations, which eventually degrade the update in the deeper soil layers.

In experiment DA_HSMLoc_DV, both distance localization and variable localization are used. Therefore, the state 


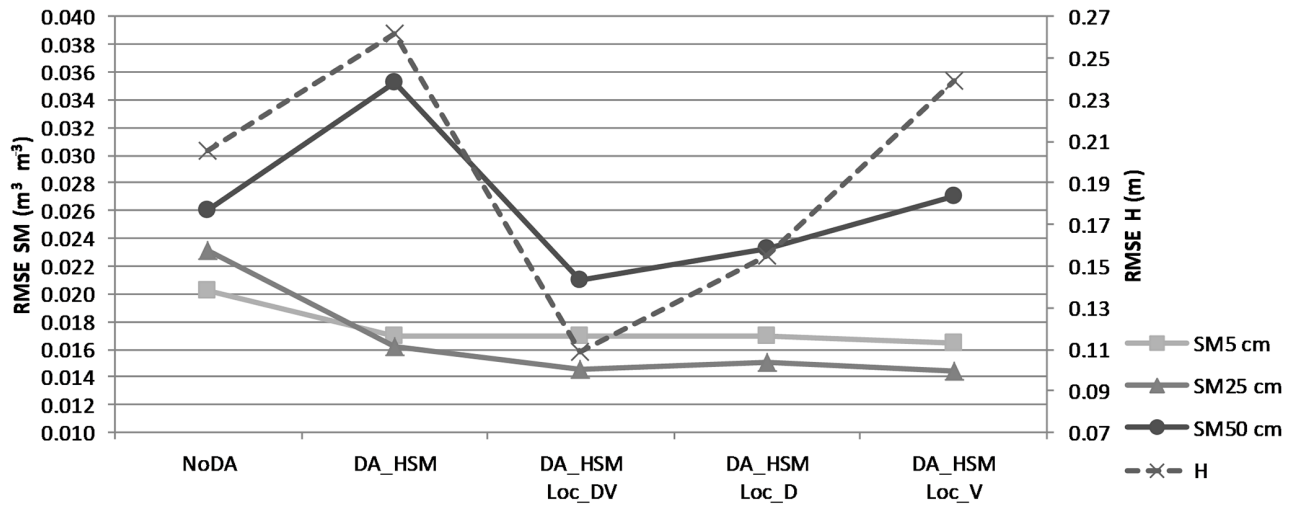

Figure 5. Spatially and temporally averaged RMSE of groundwater head and soil moisture at different depths for each multivariate assimilation experiment in the Karup catchment. The left axis represents soil moisture and the right axis head.

updates are spatially localized for each variable and the correlation between the two variables is neglected. Particularly in this case, when there is only soil moisture observation assimilated, the updates are limited to the upper $1 \mathrm{~m}$ soil moisture profile, while no correction is made for head. When both types of observation are assimilated, the corrections are made for each variable using its own error information. We can see from Fig. 5 that the experiment shows an overall improved result.

In experiment DA_HSMLoc_D, distance localization is applied to head and soil moisture, but variable localization is not included. In this case, regardless of observation type, the soil moisture is corrected within $1 \mathrm{~m}$ depth together with head. The result from this experiment shows an improved estimate for soil moisture at 5 and $25 \mathrm{~cm}$, together with groundwater head. However, the soil moisture at $50 \mathrm{~cm}$ is slightly worsened. This indicates that the correlation between surface soil moisture and groundwater head estimated from the ensemble is valid and improves the assimilation performance. Compared to DA_HSM, the result shows that excluding the error information from deeper soils (below $1 \mathrm{~m}$ to saturation) reduces spurious correlations and improves the performance. However, compared to DA_HSMLoc_DV, the result is slightly worse for head and deeper soil moisture.

In experiment DA_HSMLoc_V, distance localization is off and variable localization is applied. This means that the error information from one variable is used to update the entire domain of its own variable but does not affect the other variable. The result indicates worse assimilation performance for soil moisture at $50 \mathrm{~cm}$ and for groundwater head. One potential reason is that the lower layers of the unsaturated zone are usually fully saturated but in this experiment corrected by the surface soil moisture observation, while the groundwater head is corrected by the head observation. Potential inconsistencies may exist with these two updates.

\subsection{Different ensemble size}

As mentioned in Sect. 3.2, localization allows the ensemble filters to work properly with a limited ensemble size. The above experiments are based on an ensemble size of 60 , which is determined by balancing both assimilation performance and computational time. Some of the experiments are repeated for ensemble sizes of 30 and 90 respectively to analyse how the assimilation performance and the choice of localization are affected by the ensemble size. The results are shown in Fig. 6.

As can be seen from Fig. 6, in the experiment assimilating head without localization (DA_H), increasing the ensemble size (from 30 to 90 ) slightly improves the head estimation. However, the performance difference between ensemble sizes of 60 and 90 is small. When localization is used, the performances with all ensemble sizes are very similar (DA_Hloc).

In the experiment assimilating soil moisture at $5 \mathrm{~cm}$ depth without localization (DA_SM5), increasing the ensemble size also improves the soil moisture at deeper depths. This indicates that using only an ensemble size of 30 introduces a spurious correlation between surface soil and deeper soil, which is reduced with larger ensemble sizes. An ensemble size of 30 also leads to a much worse result for groundwater head compared to ensemble sizes of 60 or 90 . When localization is used (DA_SM5Loc), the assimilation performance is similar using the three ensemble sizes. Compared to the DA_SM5, there is a large improvement in groundwater head when using an ensemble size of 30 .

When both soil moisture (at 5 and $25 \mathrm{~cm}$ depths) and head are assimilated without localization (DA_HSM), the performance is generally improved when increasing ensemble size. However, increasing the ensemble size to 90 still leads to a worse performance for soil moisture at $50 \mathrm{~cm}$ and groundwater head compared to the deterministic model. When localization is used (DA_HSMLoc_DV), the soil moisture at $50 \mathrm{~cm}$ and the head improves as the ensemble size in- 

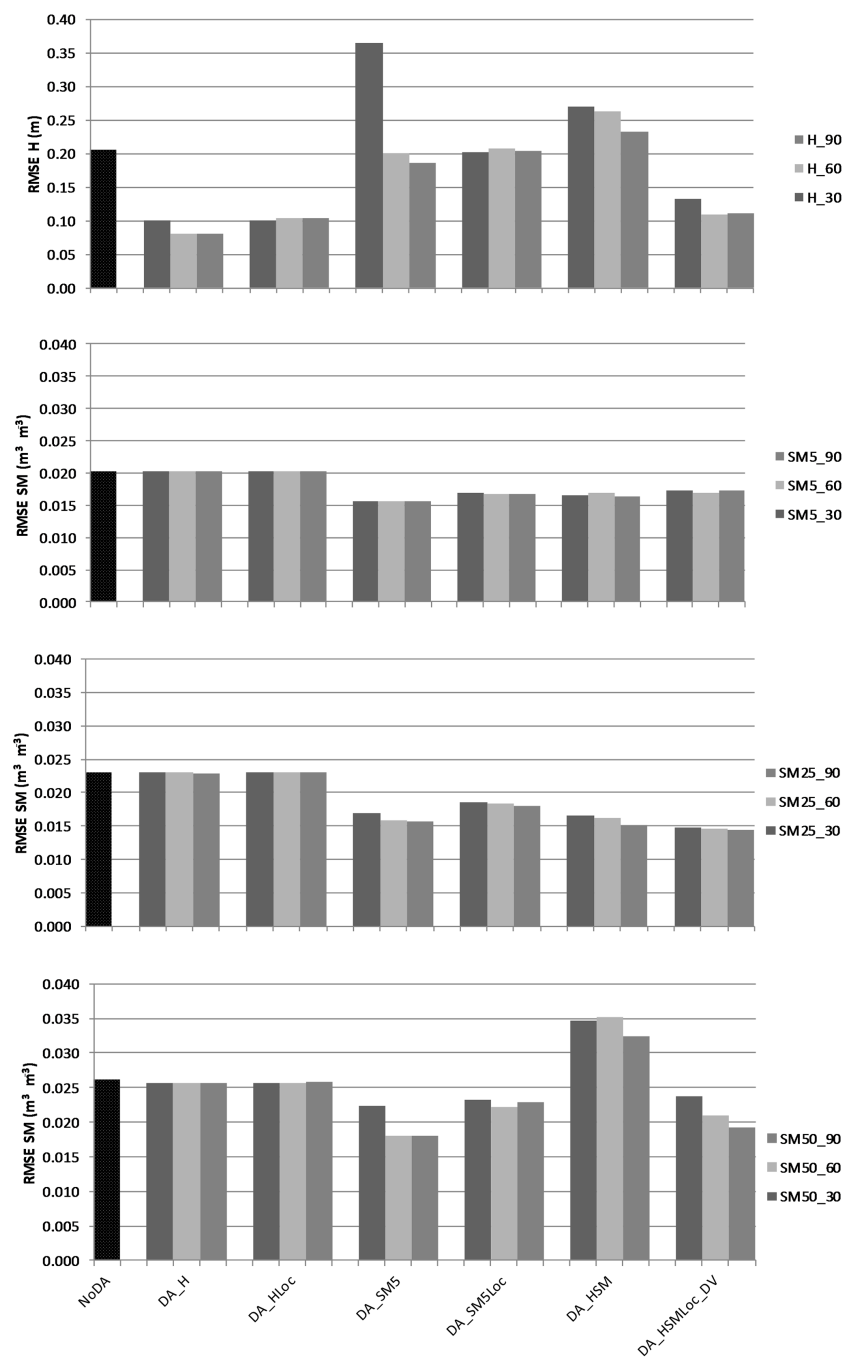

Figure 6. Results from different experiments in the Karup catchment. From top to bottom, the first panel shows the average spatial RMSE of groundwater head, and the second, third and fourth panels are the average spatial RMSE of soil moisture at 5,25 and $50 \mathrm{~cm}$ depths respectively. From left to right, the experiment names are indicated as the horizontal axis label from the bottom panel. For each experiment except NoDA, the results of three ensemble sizes $(30,60$ and 90) are represented using different colours as shown in legends.

creases. Overall, the assimilation performance increases in DA_HSMLoc_DV when increasing the ensemble size.

\subsection{Actual evapotranspiration and discharge}

Using an integrated model where the various hydrological processes are coupled, assimilation of head and soil moisture may also affect other model variables. The effects on evapotranspiration and river discharge are examined in this section. For actual evapotranspiration, we calculated average RMSE with respect to the true model of actual evapotranspiration over all 35 soil moisture observation locations during the DA
Table 3. Impact of assimilation on evapotranspiration (ET) (averaged RMSE with respect to the true model of actual evapotranspiration over all 35 soil moisture observation locations during the DA period) and discharge (Nash-Sutcliffe efficiency of discharge at the catchment outlet during the DA period) for each experiment in the Karup catchment.

\begin{tabular}{lll}
\hline & $\begin{array}{l}\text { Averaged } \\
\text { RMSE of ET } \\
\left(\mathrm{mm} \mathrm{day}^{-1}\right)\end{array}$ & $\begin{array}{l}\text { Nash-Sutcliffe } \\
\text { efficiency score of } \\
\text { discharge at the outlet }\end{array}$ \\
\hline NoDA & 0.376 & 0.936 \\
DA_H & 0.377 & 0.953 \\
DA_H_Loc & 0.376 & 0.955 \\
DA_SM5 & 0.367 & 0.923 \\
DA_SM5Loc & 0.376 & 0.941 \\
DA_SMBoth & 0.364 & 0.943 \\
DA_SMBothLoc & 0.364 & 0.944 \\
DA_HSM & 0.372 & 0.484 \\
DA_HSMLoc_DV & 0.364 & 0.932 \\
\hline
\end{tabular}

period, and for discharge the performance at the catchment outlet for the entire assimilation period is evaluated using the Nash-Sutcliffe efficiency score. The results are summarized in Table 3.

The differences in RMSE for actual evapotranspiration among all experiments are small. When $\mathrm{H}$ is assimilated alone (DA_H and DA_H_Loc), actual evapotranspiration is basically unchanged, while when soil moisture is assimilated, RMSE is marginally reduced compared to the deterministic model.

The performance of discharge is slightly improved by assimilating head (DA_H and DA_H_Loc). The improvement is mainly with respect to low flow, which is underestimated by the deterministic model. This is expected as the baseflow is corrected by updating groundwater levels. When soil moisture is assimilated with localization (DA_SM5Loc and DA_SMBothLoc), the discharge is also slightly better. However, when both variables are assimilated without localization (DA_HSM), the discharge is significantly worse, with unrealistic peak flows during spring. This is a result of the poorer head estimations in the entire domain. When localization is used for soil moisture and groundwater head (DA_HSMLoc_DV), discharge is improved significantly and comparable with the deterministic model. This also demonstrates the necessity of using localization to constrain the spatial updates.

\section{Study in the Ahlergaarde catchment}

For the Ahlergaarde catchment, we use the calibrated model to simulate a 20-year period from 1990 to 2010 to provide initial conditions for the experiment used in this study. Starting from 1 January 2010, the experiment is split into two periods: a warm-up period (1 January 2010 to 1 Novem- 
ber 2012) and a DA period (1 January 2012 to 31 December 2013). Grid-based daily precipitation $(10 \mathrm{~km})$, temperature $(20 \mathrm{~km})$ and reference evapotranspiration $(20 \mathrm{~km})$ from the Danish Meteorological Institute serve as basic meteorological data. Each ensemble member shares the same initial condition and is subject to perturbed forcing and parameter values for the warm-up period and the assimilation period. Similar to the Karup catchment experiment, daily time series of precipitation and reference evapotranspiration are perturbed at every time step using a Gaussian error model with a relative standard deviation of 0.25 multiplied by the original data. The parameter perturbations are based on the uncertainty information of 13 parameters listed in Table 2, of which the first 7 from the model calibration and the remaining 6 from the unsaturated zone are empirically defined from literature values. The unsaturated zone uncertainty is introduced by perturbing the van Genuchten $n$ for the dominant soil type at all three depths with a standard deviation of 0.05 (Ridler et al., 2014a). Overall, we try to keep the ensemble spread relatively large and model responses physically realistic.

The deterministic model used in this study, although based on a model calibrated against older data at different sites, has good skills after 2012. The model performance in terms of the hydrograph at the catchment outlet in year 2013 is shown in Fig. 10 (Obs and NoDA in the top panel), with a NashSutcliffe efficiency of 0.67 . From the hydrograph, it can be seen that the model underestimates low flows and overestimates peak flows.

\subsection{Observations}

Groundwater heads are measured bi-hourly in nine wells (Fig. 1) using Eijkelkamp mini divers. The divers were installed in these wells in November 2012, and thus the length of the time series is limited. Moreover, due to occasional instrument failure, the data coverages are further constrained and vary among the wells. In the groundwater model six numerical layers are defined (layer 1 in the bottom and layer 6 in the top). The nine wells are screened at different depths. Wells M5398, M5637, M5353, and L8008 are screened in layer 5, while wells M5373, M5647, M5844, M5393 and M5366 are screened in layer 4. When comparing in situ head measurements with model-predicted equivalents, large-level differences usually occur due to scale disparities, and are sometimes also accompanied by dynamic differences. Therefore, we calculated the average difference between observations and model simulations, and subtracted this difference from the original data. By doing so, we can avoid introducing observation bias into the assimilation system. An example of the processed observations and the open loop ensemble for well 5737 (1 November 2012 to 31 December 2013) is shown in Fig. 7 (top panel).

Soil moisture is measured at 30 sites across the catchment according to representative combinations of topography, land cover, and soil type using Decagon 5TE sensors. The dominant land uses are heath, agriculture and forest. At each site, sensors are installed at three depths, $2.5,22.5$ and $52.5 \mathrm{~cm}$, corresponding to measurement depth intervals of $0-5,20-25$ and $50-55 \mathrm{~cm}$. Measurements are taken with $30 \mathrm{~min}$ intervals.

Most of the agriculture sites are irrigated in May and June, and the soil moisture is greatly influenced, with several sudden increases during that period. However, in the model irrigation is not considered because detailed information on irrigation at the local sites is not available. Therefore, the sites where irrigation is evident from the soil moisture recordings are excluded for assimilation. In addition, a quality control to correct for systematic biases and to filter out unrealistic values has been carried out for the remaining sites. Although measurements are carried out at three depths at each site, we only use measurements at 2.5 and $22.5 \mathrm{~cm}$ depths for assimilation, as the surface/near-surface moisture is of the most importance for the exchange of water and energy between land and the atmosphere. After processing, 18 out of 30 sites are used for assimilation (Fig. 1). As an example, Fig. 7 (middle and bottom panels) shows the processed soil moisture observations and the open loop ensemble at site nw1.1 (1 November 2012 to 31 December 2013).

In addition to groundwater and soil moisture observations, discharge observations are available in the Ahlergaarde catchment at the outlet and at tributaries (right side of Fig. 1). Evapotranspiration data-based eddy covariance measurements are available from a flux station (Voulund station) located in the catchment.

\subsection{Experiment settings}

Similar to the experiment settings in the Karup catchment, the observation noise for each variable is assumed to be white Gaussian, with a homogeneous and constant standard deviation of $0.2 \mathrm{~m}$ for head and $5 \%$ for soil volumetric water content. The head and soil moisture data are interpolated to weekly and daily frequencies respectively for assimilation. Due to the larger model domain, more complex process descriptions and finer spatial resolution compared to the Karup catchment set-up, the computational time for the Ahlergaarde catchment is substantial. This implies that a larger ensemble size is unaffordable. Furthermore, the more frequent data assimilation contributes to a longer simulation time. From these considerations, an ensemble size of 50 is adopted. With a 1-year assimilation period, the simulation time is around 3 7 days, depending on the experiment settings.

With the purpose of assimilating head and soil moisture, different experiments have been carried out to investigate the assimilation performance. Considering the large model domain and fine grid, localization becomes more important here than in the previous example. Distance localization is added to both variables separately, and variable localization is used when both variables are assimilated. For groundwater head, 

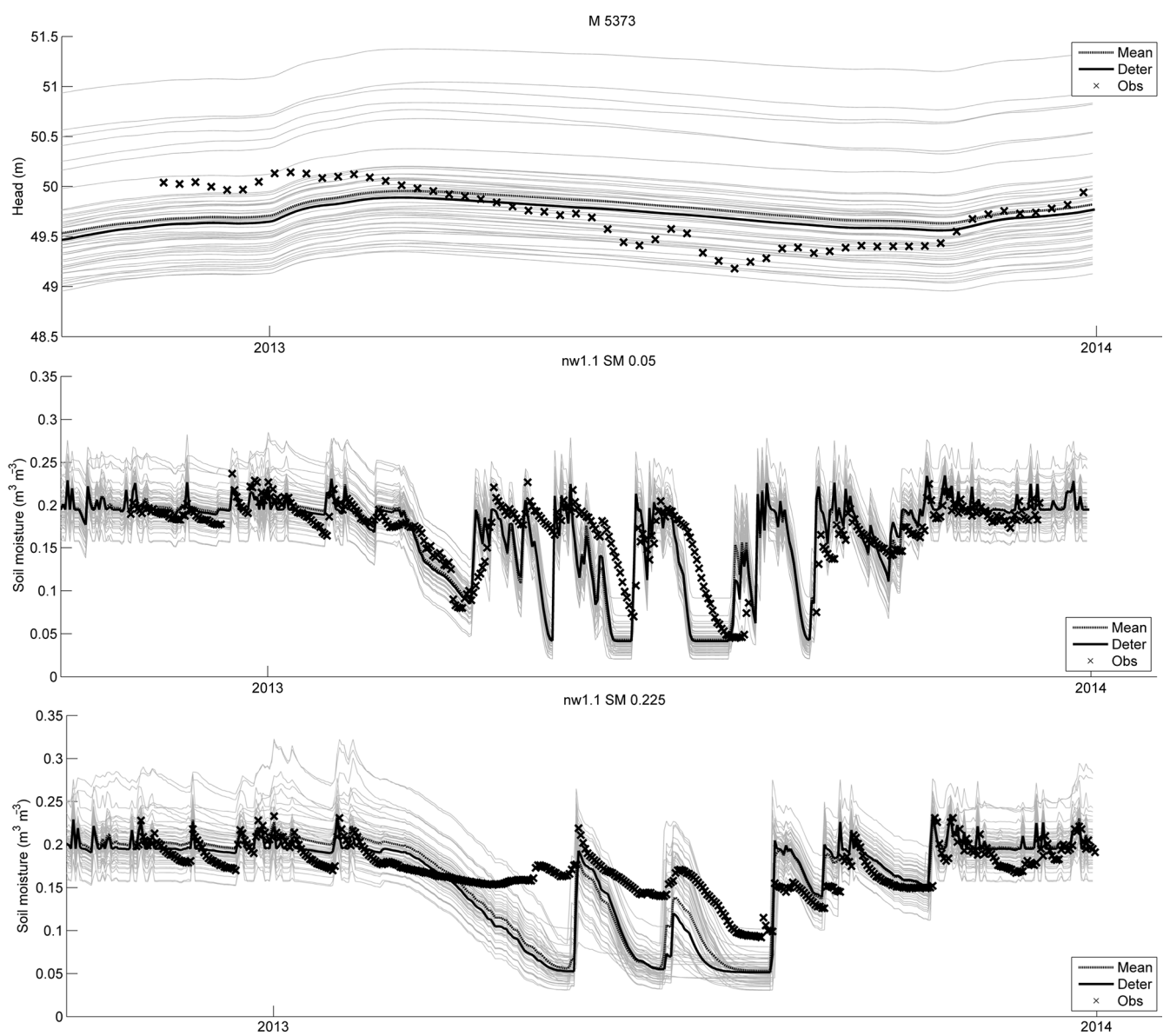

Figure 7. Top: groundwater head at well M5373. Middle: soil moisture at $2.5 \mathrm{~cm}$ at site nw1.1. Bottom: soil moisture at $22.5 \mathrm{~cm}$ depth at site nw1.1. The light grey lines (not marked in the legend) are the open-loop ensemble prediction. "Mean" (single grey line) is the ensemble average. "Deter" (dark line) is the deterministic model. "Obs" (cross marks) are the observations.

we allow for updates in all layers over the vertical. Horizontally, we use a localization radius of $5 \mathrm{~km}$ for all layers. For soil moisture, we use a horizontal localization radius of $1 \mathrm{~km}$ and a vertical localization depth of $0.5 \mathrm{~m}$ (top eight layers in the unsaturated zone). The following experiments are carried out:

- NoDA: deterministic model without DA;

- DA_HLoc: assimilating groundwater head with distance localization;

- DA_SMLoc: assimilating soil moisture (at both 2.5 and $22.5 \mathrm{~cm}$ depths) with distance localization;

- DA_HSMLoc_DV: assimilating both groundwater head and soil moisture (at both 2.5 and $22.5 \mathrm{~cm}$ depths) with variable localization and distance localization.

\subsection{Groundwater head and soil moisture}

The assimilation performance is evaluated by comparing the model output with the observations (18 sites) using
Table 4. Average RMSE of head and soil moisture $(2.5$ and $22.5 \mathrm{~cm})$ at observation locations for each experiment in the Ahlergaarde catchment.

\begin{tabular}{llll}
\hline & \multicolumn{3}{c}{ Average RMSE } \\
\cline { 2 - 4 } & of head & \multicolumn{2}{c}{ of soil moisture at } \\
\cline { 2 - 4 } & $(\mathrm{m})$ & $\begin{array}{l}2.5 \mathrm{~cm} \\
\left(\mathrm{~m}^{3} \mathrm{~m}^{-3}\right)\end{array}$ & $\begin{array}{l}22.5 \mathrm{~cm} \\
\left(\mathrm{~m}^{3} \mathrm{~m}^{-3}\right)\end{array}$ \\
\hline NoDA & 0.34 & 0.044 & 0.034 \\
DA_HLoc & 0.21 & 0.045 & 0.037 \\
DA_SMLoc & 0.34 & 0.038 & 0.024 \\
DA_HSMLoc_DV & 0.22 & 0.040 & 0.028 \\
\hline
\end{tabular}

the average RMSE over the assimilation period. The result is summarized in Table 4. In the experiment with assimilating head only (DA_HLoc), the RMSE of the head decreases from 0.34 to $0.21 \mathrm{~m}$. However, the soil moisture predictions at both depths do not improve compared to the deterministic model. In the experiment which assimilates 

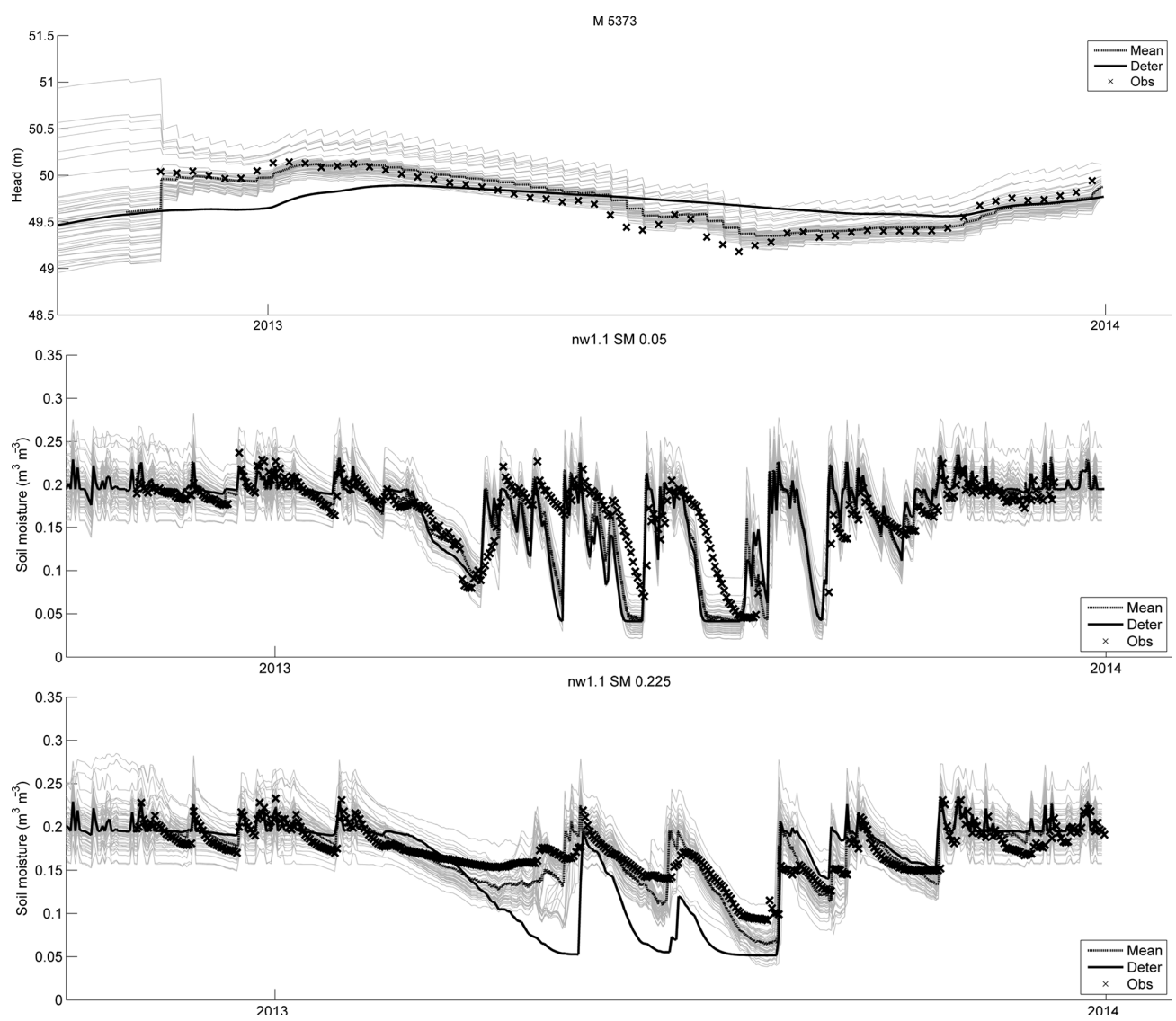

Figure 8. Top: groundwater head at well M5373. Middle: soil moisture at $2.5 \mathrm{~cm}$ at site nw1.1. Bottom: soil moisture at $22.5 \mathrm{~cm}$ depth at site nw1.1. The light grey lines (not in the legend) are ensemble predictions. "Mean" (single grey line) is the ensemble average. "Deter" (dark line) is the deterministic model. "Obs" (cross marks) are the observations. Note that the assimilation starts from 1 November 2012.

only soil moisture (DA_SMLoc), the RMSE of soil moisture at both depths decreases, especially at depth $22.5 \mathrm{~cm}$. The head estimate, however, shows a similar performance to the deterministic model. When both variables are assimilated (DA_HSMLoc_DV), the RMSE of the head decreases from 0.34 to $0.21 \mathrm{~m}$. The RMSE of soil moisture decreases from 0.044 to $0.040 \mathrm{~m}^{3} \mathrm{~m}^{-3}$ at $2.5 \mathrm{~cm}$ depth, and from 0.034 to $0.028 \mathrm{~m}^{3} \mathrm{~m}^{-3}$ at $22.5 \mathrm{~cm}$ depth.

Figure 8 shows the assimilated results for the same sites as shown in Fig. 7. Clearly, after 1 November 2012 when the DA period starts, the ensemble mean is approaching the observations, especially for the head and soil moisture at $22.5 \mathrm{~cm}$ depth. Although limited observations are assimilated, corrections are made for a large area within the model domain. Figure 9 shows spatial root mean squared differences (RMSD) of soil moisture and head at corresponding observation layers between the assimilation result and the deterministic model, which illustrates the corrections made by DA spatially. For each grid cell, the variables' time series values from the assimilated model and the deterministic model are used to calculate the RMSD.
From Fig. 9, we can clearly see the effect of the assimilation in the model domain. For soil moisture relatively large corrections are made at $22.5 \mathrm{~cm}$ depth compared to the surface layer. Compared to groundwater head, however, the soil moisture corrections are more localized. For both soil moisture and groundwater head, most of the large corrections are made at places near the locations of observations. For groundwater head in the western and south-eastern regions where no head observations are available, the corrections are generally small.

\subsection{Actual evapotranspiration and discharge}

In this section, the effect of assimilation on actual evapotranspiration and river discharge is evaluated by comparing model predictions and observations. Figure 10 compares discharge at the catchment outlet and evapotranspiration at the flux station for the different experiments. The flux station is located in the central-northern part of the catchment, with several soil moisture stations around. In both graphs in Fig. 10, only small differences are seen between different simulations. This is further substantiated by the performance measures listed in Table 5. 

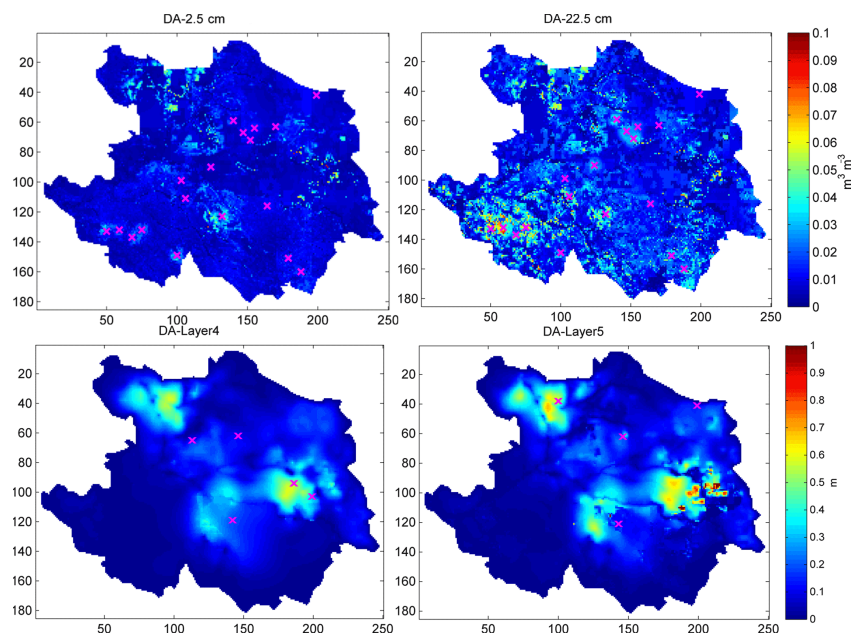

Figure 9. Spatial RMSD between assimilated and deterministic models in the Ahlergaarde catchment: soil moisture at $2.5 \mathrm{~cm}$ depth (upper left) and $22.5 \mathrm{~cm}$ depth (upper right), groundwater head at layer 4 (lower left) and layer 5 (lower right). The observation locations at each layer are marked with violet crosses.

As shown in Table 5, RMSE for actual evapotranspiration is similar in all three assimilation experiments. There is a small improvement for discharge when head is assimilated (DA_HLoc). The experiment DA_HSMLoc_DV with both variables being assimilated provides better results overall.

\section{Discussions and conclusions}

This study has investigated assimilation of soil moisture and groundwater head in an integrated hydrological model. To the best of our knowledge, this is the first study using an ETKF to assimilate these two variables in an integrated hydrological model. The method considers both distance and variable localization. The proposed method is first explored for a catchment with synthetic data and then applied to a complex model using data from real observations.

The MIKE SHE model is used as the integrated hydrological model throughout this study. In the MIKE SHE model, the saturated and unsaturated zones are explicitly coupled. This is done to optimize modelling time steps used in the unsaturated zone (minutes to hours) and saturated zone (hours to days) respectively. The flux between the unsaturated and saturated zones is calculated by an iterative procedure that conserves mass for the entire column. This means that assimilation of soil moisture may have an effect on groundwater and vice versa through this explicit coupling. However, this study shows relatively weak correlations between surface soil moisture and groundwater head in the MIKE SHE model through assimilation. First, the univariate assimilation improves the state of the variable being assimilated, but does not improve the other variable. This can be seen from the experiments in both catchments. Second, in multivariate assim-
Table 5. Quantitative performance measures for evapotranspiration (ET) and discharge for each experiment in the Ahlergaarde catchment.

\begin{tabular}{lll}
\hline & $\begin{array}{l}\text { RMSE of ET } \\
\left(\mathrm{mm} \mathrm{day}^{-1}\right)\end{array}$ & $\begin{array}{l}\text { Nash-Sutcliffe } \\
\text { score of discharge } \\
\text { at the outlet }\end{array}$ \\
\hline NoDA & 0.879 & 0.673 \\
DA_HLoc & 0.919 & 0.690 \\
DA_SMLoc & 0.853 & 0.677 \\
DA_HSMLoc_DV & 0.850 & 0.691 \\
\hline
\end{tabular}

ilation, when the complete state error covariance of both variables is used for updating and spurious correlations are not cut off by localization, the filter failed to provide a reasonable result. This indicates that the unrealistic inter-variable and cross-variable correlations may exist in the model ensemble. In a similar study, Camporese et al. (2009b) showed the EnKF assimilation of surface soil moisture can actually improve the saturated zone and assimilation of groundwater head can also improve surface soil moisture, where the saturated and unsaturated zones are based on solving the 3-D Richards equation for the entire subsurface.

In the assimilation set-up, a hybrid localization scheme which consists of variable localization and distance localization has been developed and implemented in the ETKF. Localization not only provides better results, but also reduces the computational cost, as only a section of the full state is used within the filter. Similar localization approaches have been reported in hydrological models with discharge involved ( $\mathrm{Li}$ et al., 2013) as well as in other models (e.g. Kang et al., 2011). Other approaches to deal with the potential inter-variable spurious correlation include for example adaptive localization (Rasmussen et al., 2015) and using two iterative filters instead of one filter (Gharamti et al., 2013). The method used here proved to be suitable for assimilating both groundwater head and soil moisture in integrated hydrological models, and has the potential to be generalized to deal with other processes.

The impact of assimilation on discharge and evapotranspiration is analysed in the Ahlergaarde catchment with real measurements as a reference. Neither the discharge nor evapotranspiration were included in the filter state vector. However, through integrated hydrological modelling, the discharge is improved when head is assimilated, and evapotranspiration is improved when soil moisture is assimilated. Although the improvements seem to be marginal, we nevertheless see the benefits in other modules in MIKE SHE when improving the estimate of groundwater head and soil moisture.

Increasing the ensemble size is beneficial in general, especially for estimating unobserved and un-localized variables. This is because an increased ensemble size can better describe the true correlation in the state error covariance matrix. 

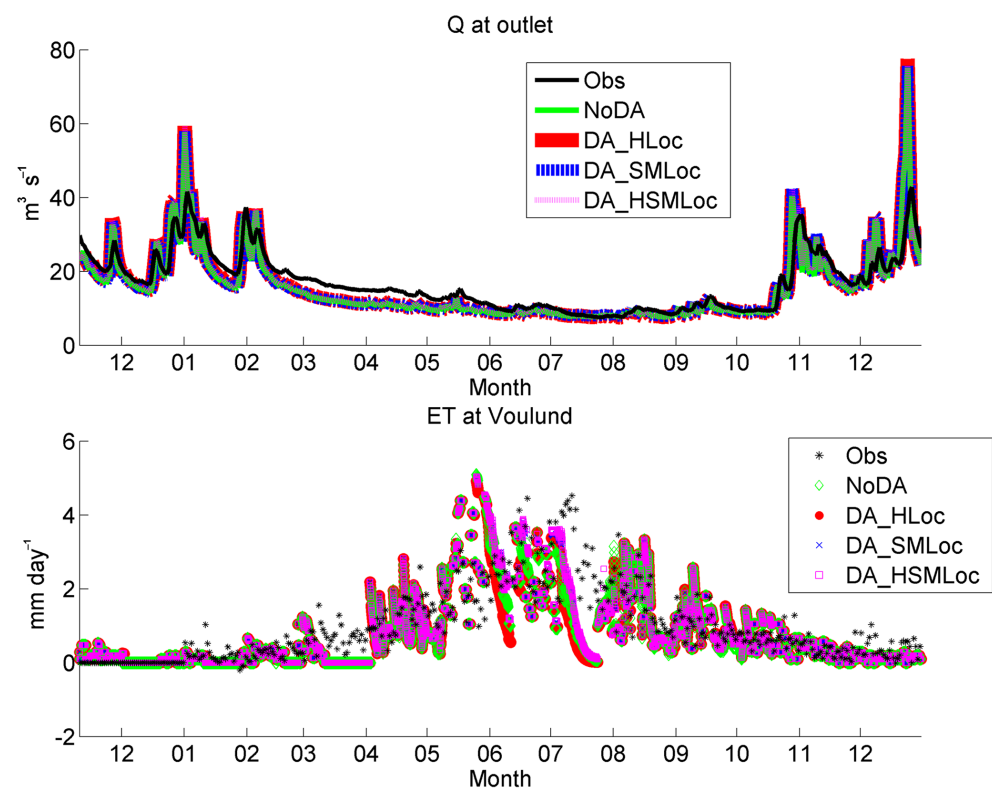

Figure 10. Top: discharge at the Ahlergaarde catchment outlet (station 250082) for each experiment and observed discharge. Bottom: actual evapotranspiration in each experiment and observed evapotranspiration at the observed station (Voulund) at Ahlergaarde catchment.

The effect of ensemble size has also been widely reported in previous studies, e.g. Xie and Zhang (2010). However, the balance between the assimilation result and the computational cost is usually considered when choosing the appropriate ensemble size for heavy models. This is an important issue for the Ahlergaarde model as the computational expenses here become substantial. Due to the time and resource limitation, the choice of ensemble size for the Ahlergaarde model is not analysed in the study, but will certainly be essential for real-time applications in future studies. In addition, the multivariable assimilation could be extended with remote sensing soil moisture and other important hydrological variables (e.g. discharge) that are not included in this study.

\section{Data availability}

The hydrological model forcing data (temperature, precipitation and reference evapotranspiration) are from the Danish Meteorological Institute (https://www.dmi.dk/vejr/arkiver/ vejrarkiv/). The field data used for model calibration and assimilation are available on the HOBE data platform (http: //www.hobe.dk/index.php/data/live-data). The soil moisture data are also a part of the International Soil Moisture Network (ISMN, https://ismn.geo.tuwien.ac.at/networks/hobe/). More detailed description of the data usage can be found in the Hydrocast project website (http://hydrocast.dhigroup. com/) and the HOBE project website (http://hobe.dk/).

Acknowledgements. The study has been carried out with the support of the Danish Council for Strategic Research as part of project
HydroCast - Hydrological Forecasting and Data Assimilation, contract no. 0603-00466B (http://hydrocast.dhigroup.com), and S.C. Van Fonden. Field data are supplied by the HOBE project funded by the VILLUM Foundation (http://www.hobecenter.dk).

Edited by: Y. Chen

Reviewed by: three anonymous referees

\section{References}

Anderson, J. L.: A local least squares framework for ensemble filtering, Mon. Weather Rev., 131, 634-642, doi:10.1175/15200493(2003)131<0634:ALLSFF>2.0.CO;2, 2003.

Bishop, C. H., Etherton, B. J., and Majumdar, S. J.: Adaptive sampling with the ensemble transform Kalman filter. Part I: Theoretical aspects, Mon. Weather Rev., 129, 420 436, doi:10.1175/1520-0493(2001)129<0420:Aswtet>2.0.Co;2, 2001.

Camporese, M., Paniconi, C., Putti, M., and Salandin, P.: Comparison of Data Assimilation Techniques for a Coupled Model of Surface and Subsurface Flow, Vadose Zone J., 8, 837-845, doi:10.2136/vzj2009.0018, 2009a.

Camporese, M., Paniconi, C., Putti, M., and Salandin, P.: Ensemble Kalman filter data assimilation for a process-based catchment scale model of surface and subsurface flow, Water Resour. Res., 45, W10421, doi:10.1029/2008wr007031, 2009 b.

Chen, Y. and Zhang, D.: Data assimilation for transient flow in geologic formations via ensemble Kalman filter, Adv. Water Resour. 29, 1107-1122, doi:10.1016/j.advwatres.2005.09.007, 2006.

Danish Meteorological Institute: Hydrological model forcing data, available at: https://www.dmi.dk/vejr/arkiver/vejrarkiv/, last access: 5 October 2016. 
De Lannoy, G. J. M., Houser, P. R., Pauwels, V. R. N., and Verhoest, N. E. C.: State and bias estimation for soil moisture profiles by an ensemble Kalman filter: Effect of assimilation depth and frequency, Water Resour. Res., 43, W06401, doi:10.1029/2006wr005100, 2007.

DHI: The MIKE SHE user and technical reference manual (2016 version), DHI, 2015.

Doherty, J.: PEST, Model-independent parameter estimation, User manual, 5th Edn., Watermark Numerical Computing, 2010.

Evensen, G.: The Ensemble Kalman Filter: theoretical formulation and practical implementation, Ocean Dynam., 53, 343-367, doi:10.1007/s10236-003-0036-9, 2003.

Gharamti, M. E., Hoteit, I., and Valstar, J.: Dual states estimation of a subsurface flow-transport coupled model using ensemble Kalman filtering, Adv. Water Resour., 60, 75-88, doi:10.1016/j.advwatres.2013.07.011, 2013.

Graham, D. N. and Butts, M. B.: Flexible, in tegrated watershed modelling with MIKE SHE, in: Watershed Models, edited by: Singh, V. P. Frevert, D. K., CRC Press, 245-272, 2005.

Gregersen, J. B., Gijsbers, P. J. A., and Westen, S. J. P.: OpenMI: Open modelling interface, J. Hydroinform., 9, 175191, doi:10.2166/hydro.2007.023, 2007.

Hamill, T. M., Whitaker, J. S., and Snyder, C.: Distance-dependent filtering of background error covariance estimates in an ensemble Kalman filter, Mon. Weather Rev., 129, 2776-2790, doi:10.1175/1520-0493(2001)129<2776:Ddfobe>2.0.Co;2, 2001.

Han, X., Li, X., He, G., Kumbhar, P., Montzka, C., Kollet, S., Miyoshi, T., Rosolem, R., Zhang, Y., Vereecken, H., and Franssen, H.-J. H.: DasPy 1.0 - the Open Source Multivariate Land Data Assimilation Framework in combination with the Community Land Model 4.5, Geosci. Model Dev. Discuss., 8, 7395-7444, doi:10.5194/gmdd-8-7395-2015, 2015.

HOBE: HOBE project website, available at: http://hobe.dk/, last access: 5 October 2016.

HydroCast - Hydrological Forecasting and Data Assimilation, available at: http://hydrocast.dhigroup.com/, last access: 5 October 2016.

International Soil Moisture Network (ISMN): Soil moisture data, available at: https://ismn.geo.tuwien.ac.at/networks/hobe/, last access: 5 October 2016.

Jensen, K. H. and Illangasekare, T. H.: HOBE: A Hydrological Observatory, Vadose Zone J., 10, 1-7, doi:10.2136/vzj2011.0006, 2011.

Kang, J.-S., Kalnay, E., Liu, J., Fung, I., Miyoshi, T., and Ide, K.: "Variable localization" in an ensemble Kalman filter: Application to the carbon cycle data assimilation, J. Geophys. Res., 116, D09110, doi:10.1029/2010JD014673, 2011.

Kurtz, W., Hendricks Franssen, H.-J., Kaiser, H.-P., and Vereecken, H.: Joint assimilation of piezometric heads and groundwater temperatures for improved modeling of riveraquifer interactions, Water Resour. Res., 50, 1665-1688, doi:10.1002/2013WR014823, 2014.

Lee, H., Seo, D.-J., and Koren, V.: Assimilation of streamflow and in situ soil moisture data into operational distributed hydrologic models: Effects of uncertainties in the data and initial model soil moisture states, Adv. Water Resour., 34, 1597-1615, doi:10.1016/j.advwatres.2011.08.012, 2011.
Li, Y., Ryu, D., Western, A. W., and Wang, Q. J.: Assimilation of stream discharge for flood forecasting: The benefits of accounting for routing time lags, Water Resour. Res., 49, 1887-1900, doi:10.1002/wrcr.20169, 2013.

Madsen, H.: Parameter estimation in distributed hydrological catchment modelling using automatic calibration with multiple objectives, Adv. Water Resour., 26, 205-216, doi:10.1016/S03091708(02)00092-1, 2003.

Montzka, C., Pauwels, V., Franssen, H.-J., Han, X., and Vereecken, H.: Multivariate and Multiscale Data Assimilation in Terrestrial Systems: A Review, Sensors, 12, 16291-16333, doi:10.3390/s121216291, 2012.

Rasmussen, J., Madsen, H., Jensen, K. H., and Refsgaard, J. C.: Data assimilation in integrated hydrological modeling using ensemble Kalman filtering: evaluating the effect of ensemble size and localization on filter performance, Hydrol. Earth Syst. Sci., 19, 2999-3013, doi:10.5194/hess-19-2999-2015, 2015.

Refsgaard, J. C.: Parameterisation, calibration and validation of distributed hydrological models, J. Hydrol., 198, 69-97, doi:10.1016/S0022-1694(96)03329-X, 1997.

Ridler, M. E., Madsen, H., Stisen, S., Bircher, S., and Fensholt, R.: Assimilation of SMOS-derived soil moisture in a fully integrated hydrological and soil-vegetation-atmosphere transfer model in Western Denmark, Water Resour. Res., 50, 8962-8981, doi:10.1002/2014wr015392, 2014a.

Ridler, M. E., van Velzen, N., Hummel, S., Sandholt, I., Falk, A. K., Heemink, A., and Madsen, H.: Data assimilation framework: Linking an open data assimilation library (OpenDA) to a widely adopted model interface (OpenMI), Environ. Modell. Softw., 57, 76-89, doi:10.1016/j.envsoft.2014.02.008, 2014b.

Sakov, P. and Bertino, L.: Relation between two common localisation methods for the EnKF, Comput. Geosci., 15, 225-237, doi:10.1007/s10596-010-9202-6, 2010.

Shi, Y., Davis, K. J., Zhang, F., Duffy, C. J., and Yu, X.: Parameter estimation of a physically based land surface hydrologic model using the ensemble Kalman filter: A synthetic experiment, Water Resour. Res., 50, 706-724, doi:10.1002/2013WR014070, 2014.

Visser, A., Stuurman, R., and Bierkens, M. F. P.: Real-time forecasting of water table depth and soil moisture profiles, Adv. Water Resour., 29, 692-706, doi:10.1016/j.advwatres.2005.07.011, 2006.

Wang, X., Bishop, C. H., and Julier, S. J.: Which Is Better, an Ensemble of Positive-Negative Pairs or a Centered Spherical Simplex Ensemble?, Mon. Weather Rev., 132, 1590-1605, doi:10.1175/1520-0493(2004)132<1590:wibaeo>2.0.co;2, 2004.

Whitaker, J. S. and Hamill, T. M.: Ensemble data assimilation without perturbed observations, Mon. Weather Rev., 130, 1913-1924, doi:10.1175/1520-0493(2002)130<1913:Edawpo>2.0.Co;2, 2002.

Xie, X. H. and Zhang, D. X.: Data assimilation for distributed hydrological catchment modeling via ensemble Kalman filter, Adv. Water Resour., 33, 678-690, doi:10.1016/j.advwatres.2010.03.012, 2010.

Zhang, D., Madsen, H., Ridler, M. E., Refsgaard, J. C., and Jensen, K. H.: Impact of uncertainty description on assimilating hydraulic head in the MIKE SHE distributed hydrological model, Adv. Water Resour., 86, 400-413, doi:10.1016/j.advwatres.2015.07.018, 2015. 